\title{
Implied Negation in Discourse
}

\author{
Yun Ding \\ Qingdao University of Science and Technology, Qingdao, China \\ Email: rainsdy@sina.com
}

\begin{abstract}
This essay aims at making qualitative analysis on implied negation in discourse proceeds by virtue of some linguistic theories related to this topic. The ubiquity of implied negation in discourse is owing to the speaker's need of politeness on account of face-saving theory. If it is used appropriately in conversation, it can make the conversation interesting and humorous and thus achieve a harmonious atmosphere by avoiding embarrassment caused by direct negation.
\end{abstract}

Index Terms-implied negation, co-operative principle, politeness

\section{INTRODUCTION}

The tradition view of negation as a logical operator that reverses the truth-value of a proposition, has conditioned its status as a semantic concept in much of the literature in the field. Research in pragmatics and related disciplines, however, has incorporated negation as an element that determines the creation of specified discourse pragmatic functions, such as denial. A negative utterance can be part of any functional or pragmatic classification just in the same way as affirmative utterances are, as long as their different properties are accounted for.

Unfortunately, however, most work on negation on these terms has a semantic orientation, and the examples are typically isolated sentences. Very little word has been carried out on the discourse and pragmatic properties of negation in context. The most extensive works in the field are those by Givon (1993), and Tottie (1991). Whereas the former develops a framework of negation based on the notion of negation as a prepositional modality and on the cognitive properties of negative states and events, the latter carries out a detailed computer-based study of variants of negation in English speech and writing. Other authors have also contributed to the field, either by devoting sections of grammars, or of broader studies, to the functions of negation (Halliday.1994; Lyons, 1977), or by focusing on specific aspects of its use (Horn, 1978). Thus, Horn (1978) considers the rhetorical properties of negation as a means of foregrounding and of establishing cohesion. The cohesive function of negation, in particular of lexical negation in discourse, is also mentioned by other authors (Lyons, 1977). The notion of negation as involving the denial of an assumption or a defeated expectation has also been the focus of attention of many studies, although the majority have been concerned with the psychological aspects of the processing of negation terms of sentences (Clark, 1977), rather than on the processing of negatives in discourse, be it spoken or written.

Therefore processing of negatives in discourse, especially affirmative utterances with negative meaning will be discussed in this article.

\section{TyPES OF SENTENCES WITH IMPLIED NEGATION IN DISCOURSE}

Any utterance that is produced on some particular occasion is an actual utterance. In certain situations, the utterance that is produced is very highly determined by factors which we may describe, loosely for the moment, as contextual. For example, the utterance Hello when answering the telephone or of "Good morning" upon entering a shop at a certain time of day is highly determined by the social role that the utterer is playing and his recognition of what utterance types are appropriate to this role, and by a variety of more particular contextual features. (Lyons, 1977)

As for the implied negative meaning, it can be realized as well by the following types of sentences:

\section{A. Interrogative Sentence, Especially Rhetorical Question}

Rhetorical question is asked not in order to elicit an answer but in order to state or deny something. A positive rhetorical yes-no question is like a strong negative assertion:

(1) Is that a reason for desPAIR? (Surely that is not a reason...)

(2) Can anybody doubt the WISdom of this action? (Surely no one can doubt...)

Unlike exclamatory questions these rhetorical questions have the normal rising intonation of a yes-no question, and are distinguished chiefly by the range of pitch movement.

There are also, rhetorical $w h$-questions. The positive question is equivalent to a statement in which the $w h$-element is replaced by a negative element (Quirk, 1985):

(3) Who knowslcares? (Nobody knowslcares or I don’t knowlcare.)

(4) What should I say? (There is nothing that I should say.)

Questions introduced by why do you have a positive presupposition, but a negative orientation when they have illocutionary force of directives: 
(5) Why do you make such a fuss? (You are making a lot of fuss, but shouldn't make so much fuss.)

\section{B. Imperative Sentence}

Some positive imperative sentences are often employed to convey negative meaning:

(6) Please be more careful. (You are not very careful.)

(7) Leave the tap alone. (Don't touch the tap.)

(8) Keep off the grass. (Don't step on the grass)

\section{Exclamative Exclamation $\backslash$ Exclamatory Sentence}

Nonsentence

(i) Exclamatory noun phrases modified by a restrictive relative clause (in most instances with zero relative) generally express disapproval:

(9) The clothes she wears! (I really don't like the clothes she wears.)

(10) The fuss they made!

(ii) Also expressing scornful disapproval are exclamatory phrases consisting of a noun phrase, generally a pronoun, followed by and, and other noun phrase with a matching possessive pronoun:

You and your statistics! (I deplore the way you so frequently resort to statistics; I am not satisfied with...)

(11) Him and his malicious gossip!

(iii) Exclamatory prepositional phrases beginning with of all express strong disapproval:

(12) Of all the impudence! (13) Of all the stupid things to say!

(iv) Exclamatory noun or adjective phrase may also express disapproval:

(14) Dirty place!

Apart from the subordinate $w h$-clause discussed before, several other kinds of clause that are subordinate in form are used as irregular sentences. They generally have the illocutionary force of exclamations, the omission of the matrix clause being mimetic of speechless amazement:

(i) That-clause generally contains the putative should that may accompany expressions of surprise. They typically convey disapproval or regret:

(15) That you could ever want to marry such a man!

(16)That it should come to this!

These sentences are distinctly more formal than the infinitive sentences in (ii) below.

(ii) To-infinitive clauses convey kinds of illocutionary force similar to those for that-clause. A common type begins with To think (that), and is very similar in its illocutionary force to the that-clause in (i), though less formal:

(17) To think that she could be so ruthless! (She shouldn't be so....)

(18) To think that I was a millionaire!

The implied subject in such sentence is the first pronoun. It may be interpreted as something like "It surprises me to think..." or "It surprises one to think...", though the fuller forms are not exclamatory. When the infinitive clause begins with some other verb than think, its subject is understood from an introductory subject or vocative, or it may be apparent from the previous context:

(19) You fool, to forget your wedding anniversary!

(20) You're going to be in trouble. To say something like that!

(iii) Infinitive clauses introduced by oh express an exclamatory wish. The style is poetic or archaic, expect when jocular:

(21) Oh to be in England! (I wish I were in England.)

(22) Oh to be free! (I wish I were free.)

\section{Ironic Sentence}

By using a word in such an ironic way that it could convey a meaning opposite to its literally meaning. Typically there is an intention to mock:

(23) A fine daughter you raised. (Your daughter is not fine at all)

(24) You are telling me. (I don't need you to tell me.)

Of course, irony can be fulfilled by the sentence types or special structure mentioned above, e.g.:

(25) Much I care! (I don't care at all.)

(26) I am damned if it is true. (It is not true certainly)

Certainly, the above types of sentences conveying negative meaning are far from enough, since the conversation is various in forms. Nevertheless, I just illustrate those sentences that could be summarized, as their structures are different from the common ones. The ordinary sentences with implied negative meaning are also inside this category. Now that we know the variations of sentences with negative meaning, it is pertinent to inquire why they have some magic power? Actually, these sentences are some kind of implicatures we will deal with next. The following is the explanation.

\section{GENERATION OF IMPLIED NEGATION IN DiSCOURSE}




\section{A. Grice's Co-operative Principle}

Assuming that we now have some idea as to what implicatures are, a natural question is how to explain their generation. Implicatures clearly play an important part in communication and equally clearly, there is a great deal of consensus as to what the implicatures of particular situated utterances are. There must therefore exist a principle mechanism (mechanisms), which licenses a set of inferences, given an utterances and it setting.

First of all, we need know Grice's conversational maxims.

No doubt the major contribution to our understanding of this type of process, however, has been Grice's theory of "conversational implicature". Grice proposed a system of 'conversational logic' i.e. intuitive principles which are supposed to guide conversational interaction in keeping with a general 'co-operative principle' (often referred to in the literature as CP). 'Maxims' differ from 'rules' in that they are seen as generally valid rather than to count only for specified and specified cases. The CP says:

Make your conversational contribution such as is required, at the stage at which it occurs, by the accepted purpose and direction of the talk exchange in which you are engaged. (Grice, 1975)

The maxims are:

a. The maxim of quantity

(i) Make your contribution as in formative as is required for current purpose of the exchange.

(ii) Do not make your contribution more informative than is required.

b. The maxim of quality: Try to make your contribution one that is true.

(i) Do not say what you believe to be false.

(ii) Do not say that for which you lace adequate evidence.

c. The maxim of relation (later called relevance): Be relevant

$\mathrm{d}$.The maxim of manner: Be perspicuous.

(i) Avoid obscurity of expression (ii) Avoid ambiguity (iii) Be brief (iv) Be orderly

It is generally regarded as being less important than the others; it is largely self-explanatory, except that:

(i) Ambiguity, of course, means "ambiguity in context": it is virtually impossible to avoid potential ambiguity.

(ii) Not everybody knows what prolixity means! The Concise Oxford Dictionary has lengthy, tediously wordy".

(iii) The orderliness Grice had in mind was recounting events in the order that they occurred (if temporal relations are not explicitly signaled).

In short, these maxims specify what participants have to do in order to converse in a maximally efficient, rational co-operative way; they should speak sincerely, relevantly, and clearly while providing sufficient information.

e. The nature of the maxims

A number of points need to be made about the nature of the maxims. The first is that they are not rules, after the fashion of grammatical rules. They are much more flexible, more like guidelines. Infringing a rule of grammar leads to an ill-formed utterance; the maxims can be creatively infringed, frequently conflict with one another, and are to be followed by and large, to the least of one's ability.

Grice is at pains to emphasize that the maxims are not culture-bound conventions like table manners: they are rationally based, and would hence be expected to be observable in any human society. In fact, Grice claims that similar maxims govern any co-operative activity. So, for instance, if workman A asks fellow workman B to pass him a chisel, B does not hand over a saw (maxim of quality), give two chisels (maxim of quantity), hand over a saw when none has been requested or seems necessary (maxim of relation), nor does he indicate the location of the chisel by means of a riddle (maxim of manner). This does not entail, however, that there are no cultural differences to be observed. One way in which cultures can differ is in the relative importance allotted to the maxims. For instance, a strict adherence to the maxim of quality may lead to no information at all being given. In some cultures, this may come across as rudeness, and to avoid this result, it may by preferable to provide fictious information in order to make up a seemly response.

\section{B. How Conversational Implicatures Arise_Flouting Maxims}

It is now to consider the question of how implicatures arise. In Grice's system, there are two main mechanisms. The first, which gives rise to what are sometimes called standard implicarures require the assumption that the speaker is doing their best to follow the co-operative principle, even though the result may not be the best, from the point view of the hearer. The second mechanism involves a deliberate flouting of the maxim, which is intended to be perceived as deliberate by the hearer, but at the same time as none the less intending a sincere communication, that is to say, without abandonment of the co-operative principle. But since speakers are expected to be co-operative by using language in accordance with the maxims, any clear breaching or flouting will be interpreted by a co-operative interlocutor as a conscious act signaling special (implicit) meaning. The inference based leads to conversational implicatures, in addition to or different from the 'standard 'or 'conventional' ones, i.e. aspects of meaning that go even further beyond what is literally said. That is to say: If someone drastically and dramatically deviates from maxim-type behavior, then his utterances are still read as under-lying some maxim, the speaker can force the hearer to do extensive inferencing to some set of propositions, such that if the speaker can be assumed to be conveying these then at least the over-arching co-operative principle would be sustained. Some examples will follow.

Both kinds of implicature are of great interest. Since implied negation in discourse is fulfilled by certain 
conversational implicature, I shall only concentrate on that, especially those conversational implicature indicating negative meaning.

Flouting Maxims

a) The maxim of quality:

This maxim might be flouted in the following exchange:

(27)A: What if the USSR blockades the Gulf and all the oil? B: Oh, comes now, Britain rules the seas!

Any reasonably informed participant will know that B's utterance is blatantly false. That being so, B cannot be trying to deceive A. the only way in which the assumption that B is co-operating can be maintained is if we take B to mean something rather different from what he has actually said. Searching around for a related but co-operative proposition that B might be intending to convey, we arrive at the opposite, or negation, of what B has stated-namely that Britain doesn't rule the seas, and thus by way of Relevance to the prior utterance, the suggestion that there is nothing that Britain could do. Hence Grice claims, ironies arise and are successfully decoded.

Other Quality flouting includes the uttering of patent falsehoods as in (28):

(28) A: Teheran's in Turkey, isn't it, teacher? B: And London's in Armenia I suppose.

Where B's utterance serves to suggest that A is absurdly incorrect. Or consider the rhetorical question like (29):

(29) Was Mussolini going to be moderate?

Which if the participants believe that whatever Mussolin was, he was not moderate, is likely convey:

Mussolini was definitely not going to be moderate.

Here, by overtly violating the sincerity of a question, an implicature is generated by a flouting of the maxim of Quality-do not say something that you believe it false.

b) The maxim of quantity

The uttering of simple and obvious tautologies should, in principle, have absolutely no communicative import; however, utterances of (30),(31)

(30) Annie: Was the dessert any good? Mike: Annie, cherry pie is cherry pie.

(31) If he does it, he does it.

Note that these, by virtue of their logical forms are necessarily true; the differences we feel to lie between them, as well as their communicative import, must be almost entirely due to their pragmatic implications. An account of how they come to have communicative significance, and different communicative significances, can be given in terms of the flouting of maxim of Quantity. Since this requires that speakers be informative, the asserting of tautologies blatantly violates it. Therefore, if the assumption that the speaker is actually co-operating is to be preserved, some informative inference must be made. Thus in case of (30) it might be 'the property of cherry pie is boring, and I don't like it at all; in the case of (31), it might be 'it's no concern of ours'. Clearly these share a dismissive or topic-closing quality, but the details of what is implicated will depend upon the particular context of utterance. Incidentally, exactly how the appropriate implicatures in these cases are to be predicted remains quite unclear, although the maxim of Relevance would presumable play a crucial role.

c) The maxim of relation

Exploitations of this maxim are, as Grice notes, a little harder to find, if only because it is hard to construct responses that must be interpreted as irrelevant. But Grice provides an example like the following:

(32) Johnny: Hey Sally, let's play marbles

Mother: How is your homework getting along Johnny?

Where by Johnny's mother remind him that he may not yet be free to play.

d) The maxim of manner

Be brief: wherever we avoid some simple expression in favour of some more complex paraphrase, it may be assumed that we do not do so wantonly, but because the details are somehow relevant to the present enterprise. One example of exploitation of this maxim will suffice here:

(33) A: Let's get the kids something. B: Okey, but I veto I-C-E C-R-E-A-M-S.

Where B ostentatiously infringes the maxim of manner (be perspicuous). By spelling out the word ice-cream, and there upon conveys A that B would rather not have ice-cream mentioned directly in the present of children, in case they are thereby prompted to demands some.

Another example:

(34) Miss singer produced a series of sounds corresponding close to the score of an aria from Rigoletto.

(35) Miss singer sang an aria from Rigoletto.

By the flagrant avoidance of the simple (53) in favor of the prolix (52) (and consequent violation of the sub-maxim 'be brief'), the reviewer implicates that there was in fact such considerable difference between Miss singer's performance and those to which the term 'singing' usually applied that her performance couldn't be called 'singing' at all.

Finally, and importantly, an expression with a single meaning can give rise to different implicatures on different occasions, and indeed on any one occasion the set of associated implicatures may not be exactly determinable. For example:

(36) John is machine. 
This could convey that John's cold, or efficient or never stops working, or puffs and blows, or has little in the way of gray matter, or indeed any and all of these. Some implicatures can have creation indeterminacy in at least some cases, incompatible with the stable determinate senses usually assumed in semantic theory.

\section{How to Recognize Conversational Implicatures}

The following are amongst the criteria which have been proposed to distinguish conversational implicatures from other semantic/pragmatic phenomena with which they might be confused. These criteria are not entirely logically independent from one another.

a) Context dependence:

An expression with a single meaning (i.e. expressing the same proposition) can give rise to different conversational implicatures in different context:

(37) A: Have you cleared the table and washed the dishes?

B: I've cleared the table. (But haven't washed the dishes)

(38) A: Am I in time for supper?

B: I've cleared the table. (No, you are too late for supper)

b) Defeasibility/Cancellability

Conversational implicatures can be cancelled by additional material without contradiction or anomaly.

(39) A: Did the Minister attend the meeting and sign the agreement?

B: (i) The Minister attended the meeting.

(ii) The Minister attended the meeting; a statement will be issued later with regard to the agreement.

B's first answer as it stands creates quite a strong presumption that the Minister did not sign the agreement. However, the additional material in B (ii) suppresses the implicature: we are no longer entitled, or invited, to conclude that the agreement was not signed.

Although defeasibility or cancellability is one of the standard criteria for CI, it is none the less questionable. The reason is that adding material changes the context: there is no way of suppressing the implicature without doing this. In other words, this criterion adds nothing that is not covered by the criterion of context dependence.

c) Non-detachability

The same prepositional content in the same context will always give rise to the same conversational implicatures, in whatever form it is expressed (that is to say, the implicature is tied to meaning and not to form):

(40) A: Have you cleared the table and washed the dishes

B: I've taken all the things off the table.

d) Calculability

A conversational implicature must be calculable, using stable general principles, on the basis of conventional meaning together with contextual information. E.g.

(41) A: Do you like my new hat? B: It's pink.

If B's answer is a conversational implicature, A will surely calculate B's opinion-B doesn't like my new hat. If A couldn't understand B's implied meaning, this will not be a CI, for Grice points out that, for the addressee $\mathrm{H}$ to be able to calculate the implicature, $\mathrm{H}$ must know, or believe that he knows the facts in the following (i)-(iv):

(i)The conventional content of the sentence P uttered.

(ii)The cooperative principle and its maxims.

(iii)The context of $\mathrm{P}$ (e.g. its relevance)

(iv)Certain bits of background information.

(v)That (i)-(iv) are mutual knowledge shared by the speaker and the addressee.

This criterion serves to distinguish conversational implicatures from special arrangement whereby, for instance, two people agree (arbitrarily) that whenever one of them says X, they actually mean Y. For instance, a husband and wife might fix it between them that if one of them says "Have you seen anything of Clive recently?" it will mean "Let's leave in 15 minutes". This will not be calculable, by general principles, from the convention meaning of the utterance together with contextual information.

\section{Why Conversational Implicature Occurs? —On Politeness}

As mentioned above, CI is arisen by the flouting of maxim. Why does this occur? Leech's (1983) politeness principle has provided explicit instructions.

The Politeness Principle

Before we discuss this principle and its maxims, some discussion of politeness is necessary. Politeness is first and foremost, a matter of what is said, and not a matter of what is thought or believed. Leech expresses the politeness principle thus:

i) Minimize the expression of impolite beliefs.

This has the merit of throwing the weight on to expression. Let us rephrase the principle as follows:

ii) Choose expressions which minimally belittle the hearer's status.

The sorts of thing which may be thought to belittle the hearer's status (or, alternatively expressed, "cause the minimum loss of face to the hearer") are: 
- Treating the hearer as subservient to one's will, by desiring the hearer to do something that will cost effort, or restrict freedom, etc.

- Saying bad things about the hearer or things related to the hearer.

-Expressing pleasure at the hearer's misfortunes.

-Disagreeing with the hearer, thus denigrating the hearer's thought.

- Praising oneself, or dwelling on one's good fortune, or superiority.

The purpose of politeness is the maintenance of harmonious and smooth social relations in the face of the necessity to convey belittling messages. Of course, the nature of reality, social, psychological and physical, constrains the scope for politeness: if our world is to "work", we must respect this reality. We can think of co-operative principle as restraining influence on the politeness principle.

It is worthwhile distinguishing between positive and negative politeness. Negative politeness mitigates the effect of belittling expression:

(42) Help me to move this piano.

(43) You couldn't possibly give me a hand with this piano, would you?

Positive politeness emphasizes the hearer's positive status:

(44) Thank you, that was extremely helpful.

Generally speaking, we are more concerned, as social beings, with negatives politeness, as breakdowns in social harmony are much more likely as a result of the expression of belittling thoughts.

Certain language expressions are specialized for politeness, such as please and thank you. But the greater part of politeness comes across in the form of implicatures. As many examples mentioned above, negative meaning (disagree) is conveyed by implicaures in terms of politeness. The overall mechanism Leech proposes for the generation of implicarures via the politeness principle is similar to that proposed by Grice for the co-operative principle, each principle, is accompanied by a set of more specific maxim. There are several maxims, of course, but I only deal with those relevant to my topic in this section.

Two things emerge here. First of all, and not surprisingly, saying something good about other person is much more polite than say something bad. Leech called this:

The approbation maxim, which can be summarized as:

Minimize dispraise of the hearer.

Maximize praise of the hearer.

Second, if we have to say something bad about (dispraise) the other, it seemed to be more polite to take an indirect route. Leech pointed out that, while speakers need to observe the maxim of quality (be truthful) in representatives, they often find that this conflicts not so much with one of Grice other three maxims, but rather with the need to be polite. To resolve this clash, speakers imply a criticism rather than badly state it.

As usual, negative politeness is the more crucial; hence the first sub-maxim is the more likely to be brought into play. The effect is to tone down any criticism or unfavorable comment:

(45) A: Well, I've done it. I've dyed my hair blonde. B: You look amazing.

"You look amazing" probably implies that B did not like the blonde hair. He does this by flouting the maxim of quantity (be maximally informative). The ambiguity of amazing (amazing for its beauty or awfulness) allows the speaker to be truthful and yet somewhat more polite that the direct answer, "You look awful, and I don't like that at all!"

\section{The agreement maxim}

Agreement is a relation between the opinions of the speaker and those of the hearer. This maxim is simply:

Minimize disagreement with the hearer. Maximize agreement of the hearer.

The sub-maxims are not clearly distinct. A typical strategy is to begin with partial agreement before expressing disagreement:

(46) A: She should be sacked immediately. We can't tolerate unpunctuality.

B: * I disagree.

I agree with the general, but in this case there are mitigating circumstances.

The consideration maxim

Leech presents the consideration maxim as a separate principle, and it works just like the other maxims:

Minimize the hearer's discomfort/displeasure.

Maximize the hearer comfort/pleasure.

Negative politeness under this maxim involves the softening, by various devices, of references to painful, distressing, embarrassing or shocking events, facts or things etc. This also can produce implied negation in discourse:

(47) Wife: Will you go to the party with me tonight? You said you would last night.

Husband: *No, that's impossible.

Well, yes, I am so glad to do that. But you know, honey, I have an important appointment tonight, so I am sorry. If I have time, I will ...

Miscellaneous principle

Leech proposes two more principles, independent of both the politeness principle and the co-operative principle. We shall not propose additional principle, but follow the Gricean example and speak instead of the deliberate flouting of 
the principle of politeness. There are two basic possibilities here: one can be superficially polite, but patently insincere, leading to rudeness by implicature, or one can be superficially rude, but patently sincere, leading to politeness by implicature. The insincerity must be indeed patent, for the trick to work, and the strategy carries a certain risk that one might be taken at one's word. Leech groups the following sort of example under what he calls the irony principle:

(48) Do help yourself! (to someone who helps himself unjustifiably, without invitation)

(49) Well, thank you very much! (Someone parks his car in front of your drive, so you can't get out)

The opposite sort case comes under Leech's banter principle (actually both involve a type of irony):

(50) Look, what the cat's just brought in.

(51) You stupid bitch! (to a close friend who's just done something daft)

The implicature here is that the relationship is so solid that politeness is not necessary, and this is, of course a polite implicaturee.

Eventually, the irony principle, again, offers a sound theoretical foundation for those ironic sentences with negative meaning, such as (23), (24) and so on.

Take the following example as further illustration:

(52) Annie: Was the dessert any good?

Mike: Annie, cherry pie is cherry pie.

Mike's answer breaches the maxim of quantity (co-operative principle) - make your contribution as informative as is required for current purpose of the exchange. However, if Mike directly expressed his negative opinion, Annie would feel embarrassed. Therefore, Mike employs implication to his expression, which is the very application of politeness principle: the agreement maxim, the praise maxim, and the consideration maxim — all emphasized on minimizing disagreement, dispraise and discomfort with the hearer.

Leech observed that the relationship between indirectness and politeness could be quite complicated. The social distance between the speaker and the hearer, and the need to feel accepted by other people, can also have a significant effect on how we interpret the politeness of an utterance, and indeed how we structure our own utterances.

We see that between friends an indirect and more formal directive like "would you mind passing me the salt or could you please pass me the salt?" can sound rather unfriendly. However, with someone you do not know very well, this seems more appropriate. In the case of the military, the authority of a higher rank is so absolute that politeness does not really seem an appropriate criterion to apply.

Virtually, a framework to deal with these kinds of issues was developed by Brown and Levinson (1978). They have set out to develop an explicit model of politeness which will have validity across cultures. The general idea is to understand various strategies for interactional behavior based on the data that people engage in rational behavior to achieve satisfaction of certain wants. The wants related to politeness are the wants of face, "Something that is emotionally invested, and that can be lost, maintained, or enhanced, and must be constantly attended to in interaction." (Brown and Levinson, 1978). The concept is directly related to the folk-expression 'lose face', which is about being embarrassed or humiliated. There are two kinds of face. One is positive face, the positive consistent self-image that we have and want to be appreciated and approved of by at least some other people. Positive politeness orients to preserving the positive face of other people when we use positive politeness, we use speech strategies that emphasize our solidarity with the hearer, such as Nicknames, informal pronunciation, shared dialect or slang expressions and so on. The other is negative face, or the right to territories, freedom of action and freedom from imposition, essentially the want that our actions be not impeded by others. Negative politeness orients to preserving the negative face of other people. This is much more likely if there is a social distance between the speaker and hearer. When we use speech strategies that emphasize our defense for the hearer. Nicknames, slang, and informal pronunciation tend to be avoided and requests tend to be more indirect and impersonal. The rational actions we take to preserve both kinds of face for ourselves and the people we interact with essentially add up to politeness.

A strengthen of Brown and Levinson approach over the rule-oriented presentations of politeness by Leech is that Brown and Levinson are attempting to explain politeness by deriving it from more fundamental notions of what it is to be a human being (being rational and having face wants). According to Leech's maxims of politeness, we can understand politeness phenomena in terms of these rules, but we fail to learn very much about why they should be such rule in the first place. Granted, Brown and Levinson ask us to accept at the start that people are rational and have two kinds of face wants, but this is much deeper starting point for explanation that starting with rules designed specifically for politeness itself.

We clearly attach great importance to 'speaking politely'. This aspect of the communicative process was largely ignored by Grice. Yet, the need to be polite can often account for why we choose to imply rather than assert an idea.

Overall, when we talk, we often observe the co-operative principle, but on certain occasions, we flout some maxims, thus creating conversational implicature, on account of politeness, which, surely, is in an attempt to save the hearer's face-both positive and negative. Therefore, it is quite luminous how and why implied negation in discourse is generated: belonging to conversational implicature, it is triggered by ostentatiously flouting co-operative principle on the ground of politeness for the purpose of saving hearer's face. Thus, owing to the four distinguished linguists implied negation in discourse has been justified in this essay. 


\section{REFERENCES}

[1] Bolinger, D. (1977). Meaning and Form, London: Longman. 21-35

[2] Brown, N. and Levinspm. S. (1987). Politeness: Some Universal in Language Usage. Cambridge: Cambridge University.

[3] Brown, P. and Levinsin, S. (1978.) universals in Language Usage Politeness phenomena in Goody, E. (ed), Cambridge: Cambridge University.

[4] Clark, H.H. (1977). Psychology and Language. New York: Harcourt BraceJovanovich.

[5] Downing, L.H. (2000). Negations, Text World and Discourse, the Pragmatics of Fiction. Ablex Publishing Corporation Stamford, Conntiut. 53

[6] Givon, T. (1993). English in Grammar: a function-based Introduction. Amsterdam: John Benjamins Pub, Co.

[7] Grice, H.P. (1975). Logic and Conversation. In P.Cole and J.L. Morgan (eds) (41-58)

[8] Halliday, M. A. K. and Husan, R. (1985). Language, context, and Test: a social-semiotic perspective. Language and Learning (3) Geelong, vic: Deakin University Press.

[9] Klima, E.S (1964). Negation in English, in Fodor and Katz (eds). The structure of Language. Englewood Cliff, N.J.: Prentice-Hall. 246-323

[10] Leech, G.N. (1983). Principle of Pragmatics. London: Longman

[11] Leech, G.N. (1994) .A Communicative Grammar of English $2^{\text {nd }}$ ed. Longman Singapore Publishers Ltd.

[12] Levinson, S. C. (1983). Pragmatics. Cambridge: Cambridge University Press.109-125

[13] Tottie, G. (1991). Negation in English Speech and Writing: a Study in Variation. New York: Academic Press, INC.

Yun Ding was born in Qingdao, China in 1976. She received his M.A degree in linguistics from Dalian Maritime University, China in 2003.

She is currently lecturer in Foreign Languages Department, Qingdao University of Science and Technology, Qingdao, China. Her research interests include applied linguistics and language teaching. 